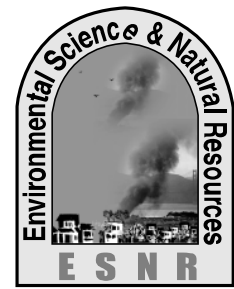

J. Environ. Sci. \& Natural Resources, 7(2):105-109, 2014 ISSN 1999-7361

\title{
An Investigation on the Pattern of Land Use Change in Dhaka City Using
} Remote Sensing and GIS Application

\author{
M. N. Uddin ${ }^{1}$, M. F. Anwar ${ }^{2}$, M. T. Rahman ${ }^{2}$ and M. N. Mobin ${ }^{3}$ \\ ${ }^{1}$ Water Resource Development, IWFM, \\ Bangladesh University of Engineering and Technology (BUET), Dhaka \\ ${ }^{2}$ Department of Environment (DoE), Dhaka \\ ${ }^{3}$ Department of Environmental Science, Bangladesh Agricultural University, Mymensingh
}

\begin{abstract}
This study assessed the extent and trend of landuse/cover change in three selected area of Dhaka city, Bangladesh. This paper examined the use of GIS and Remote Sensing in mapping Land Use/Land Cover in Dhaka city of Landsat imageries of 1960, 2000 and 2014 were downloaded from the Landsat website and to detect the changes that has taken place in this status between these periods. Remote sensing and GIS based software (ILWIS) were used to produce and analysis the land use maps and least square method was functioned to identify the trend of land use change in the study areas. The images were analyzed using unsupervised classification approach in ILWIS 4.1 environment. The present study expressed the experiences of unplanned land use change in Dhaka city. And it is found that the study area follows the pattern of urbanization without planned development. Consequently, the pattern of unplanned land use change in Dhaka city will make it a haphazard city in World.
\end{abstract}

Key words: GIS, Land use change, Least square method, Location quotient method, Remote Sensing

\section{Introduction}

Land use/cover changes have emerged as a global phenomenon and perhaps the most significant regional anthropogenic disturbance to the environment, especially in the 20th Century because, dramatic land use/cover changes that would have once required centuries now take place within a few decades and Africa is said to have the fastest rate of deforestation in the world as a result of overdependence on primary resources (Ademiluyi et al., 2008). In essence both land use/cover changes are products of prevailing interacting natural and anthropogenic processes by human activities therefore, land use/cover change detection allows for the identification of major processes of change (Fasona and Omojola, 2005). The driving force for most landuse/cover changes is population growth (Ramankutty et al., 2002b) although there are several other interacting factors involved. There is a need to understand land use/cover changes and its effect on the overall ecosystems (Lambin et al., 2003) as well as understanding local patterns and processes is important since land use/cover change is closely linked to the sustainability of socio-economic development (Lambin et al., 1999). It is increasingly evident that a concatenation of variables interacts across spatial and temporal scales to cause land use/cover changes and these casual clusters vary across regions and time (Mather, 1999) and areas affected by degradation can be identified and mapped from Landsat Thematic Mapper (TM) images (Raina et al., 1993). Consequently, in order to cope with the variability, it is vital to understand the past and present scenarios of land use/cover so as to device appropriate adaptive mechanisms for enhanced sustainability. Therefore, this study seeks to assess the extent and trend of land use/cover change. The effects of natural processes (e.g., geological, vegetation succession) on landscape change are normally slow with punctuations caused by cataclysmic events, such as meteor strikes, volcanic activity, or fire. Anthropogenic changes occur at higher rates of speed (Antrop, 2000). However, change is usually incremental and the rate of change may be slower than most people can perceive which can lead to subjectivity when interpreting landscape changes (Antrop, 2000). Human perceptions of landscape directly influence future landscape conditions (Nassauer, 1995); thus, inaccurate or misinformed perceptions by the public have the potential to increase difficulty in policy, planning, or management decision-making processes. In our field of study, wildlife ecology and management, the public may perceive lower populations of wildlife during relatively short time periods. However, people may not perceive trajectories in landscape change that may be the cause of wildlife population fluctuations. The ecological function affected by decisions that cause landscape change may be hidden (Nassauer, 1992). Ecological systems are both complex and dynamic, often making perception of change by landscape inhabitants difficult (Nassauer, 1992). Biologists often simplify systems during landscape studies by concentrating on very finite units of time and space. Limits of human understanding of such complex systems, among other constraints, necessitate this simplicity. However, descriptive studies that are broad in both space and time have the potential to be insightful to landscape inhabitants, as well as to decision-makers.Remote Sensing (RS) and Geographic Information System (GIS) are now providing new tools for advanced ecosystem management. The collection of remotely sensed data facilitates the synoptic analyses of Earth - 
system function, patterning, and change at local, regional and global scales over time; such data also provide an important link between intensive, localized ecological research and regional, national and international conservation and management of biological diversity (Wilkie and Finn, 1996).

The aim of this study is to prepare a map out the status of land use land cover of Dhaka City between 1960 and 2014 with a view to detecting the land consumption rate and the changes that has taken place in this status particularly in the built-up land so as to predict possible changes that might take place in this status using both Geographic Information System and Remote Sensing data.

\section{Materials and Methods}

Study area

Dhaka City is solely located in Bangladesh, in the southern part of the district of Dhaka. The study area lies between $23^{\circ} 44^{\prime}$ and $24^{0} 02^{\prime}$ north latitude and $90^{\circ} 12^{\prime}$ and $90^{\circ} 26^{\prime}$ east longitudes; and the total area about 414.68 sq. km (Figure 1).

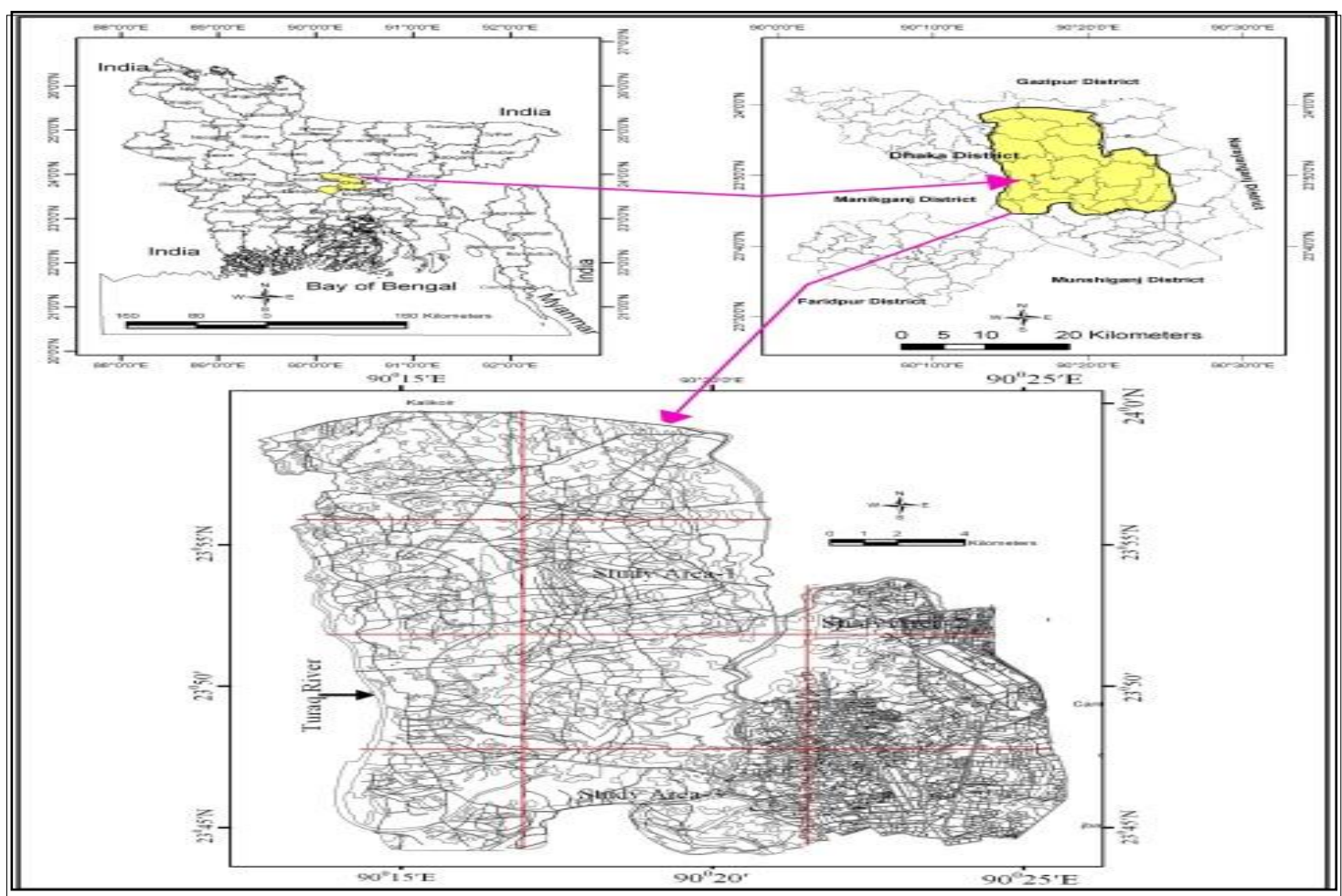

Fig. 1. Geographical Location of the Study Area (Source: Prepared based on Banglapedia, 2004)

The city has developed on the higher elevated Pleistocene terrace land or Order Alluvium of the central part of Bangladesh, otherwise referred to as the Madhupur-BhawalGarh Region. In addition, a substantial portion of the adjoining low-lying areas has recently been brought under the structured zones of the city due to the accelerated rate of the urban growth in Dhaka (Asaduzzaman and Rob 1997). The city's population suddenly increased to $2,068,353$ in 1974, it began to expand in all directions including the low-lying areas of the north and north-west, such as Uttara, Tonge and Ashulia area; and to the west including the areas of Shyamoli, Western Mohgammadpur, Kallyanpur and Amin Bazar area (Census of Bangladesh 1974).

\section{Data acquired and sources}

To derive the land use changes from the topographic map and satellite images, digital image processing technique was performed. The land use areas of 1960 were digitized, edited and leveled from the topographic map and Landsat TM image of 2000 (Variable); and Google image of 2014(Variable) were used in this study to produce land use/cover categories for the year 2000 and 2014 respectively. Afterwards, land uses were extracted from the classified maps of 1960, 2000 and 2014. The satellite image of 2000 and 2014 was collected in ERDAS Imagine (*.img) format. This image was loaded into computer memory directly from the CD (compact disk). Topographic map of 1960 were collected in the bitmap (*.bmp) format. These photographs were imported to $(*$.img) format to process the data using ERDAS Imagine software.

\section{Methods selection}

Geo-referencing was performed to render real world coordinates to the images to avoid geometric distortion. Topographic map of 1960 contain multiscale geometric distortion. The satellite images of 2000 and 2014 do not contain multi-scale geometric distortion; thus second order polynomial transformation was used for this image. For calculating the transformation matrix, 16 Ground 
Control Points (GCP) were used. The GCPs were derived from a geo-referenced image. The projection system used for the images was Lambert Conformal Conic (LCC). The geo-referenced two strips of topographic maps were mosaic to obtain the image of the whole study area. Then thematic data layers were generated from the geo-referenced images using on screen digitization technique. Data layers were generated in ArcInfo vector format using the digitization tools of ERDAS Imagine software. ArcInfo vector data layers generated from the images to render the GIS standard of the data. The spatial analyses of the thematic data layers were performed to generate composite data layers from the two images. Topographic maps coverage of individual type of land use for the year 1960, 2000 and 2014 was calculated and the disparities between them were estimated. Changes were illustrated through map generation using ILWIS 4.1 soft-ware as described in result section. It was observed from the land use map of 1960, 2000 and 2014 for identifying the rapid land use change areas using Location Quotient (LQ) method (Mack and Jacobson, 1996). The major land use change areas were selected through Location Quotient (LQ) formula was used in the study area.

The formula for computing Location Quotient is:

$$
\mathrm{LQ}=\frac{\mathrm{e}_{\mathrm{i}} / \mathrm{e}}{\mathrm{E}_{\mathrm{i}} / \mathrm{E}}
$$

Where,

ei = Local area in Grid-A; e = Total local area;

$\mathrm{Ei}=$ Reference area of the study area;

$\mathrm{E}=$ Total reference area of the study area.

Thereby, land use trend is used as one component for the development of a sustainable spatial change tool for analyzing suburbanization. The least square method is a very popular technique which is used to trend of land use change in the study area. It is one of the oldest techniques of modern statistics as it was first published in 1805 by the French mathematician Legendre in a now classic memoir. Now a day, the least square method is widely used to find or estimate the numerical values of the parameters to fit a function to a set of data and to characterize the statistical properties of estimates.

\section{Results and Discussion}

Dhaka city has faced its highest rate of physical and population growth during 1981-1991, with the population doubling during that decade and the city expanding from 510 sq. $\mathrm{km}$ to 1353 sq. km. The city now includes the surrounding areas of the north side Gazirpur, north-west Savar Thana and the south-west part of Keraniganj Thana (BBS 1991). In 1995, a new master plan was prepared for the further development of Dhaka city and the recent construction of a bridge over the Turagriver has encouraged the expansion of Dhaka city in a northerly direction to the other side of the river. A second bridge which is likely to be completed within the next five years will further increase this process (Siddiqui et al., 2000). However, the expansion of Dhaka City is constrained by physical barriers such as the low-lying flood prone areas around the city. Also, valuable agricultural and forest land will have to be sacrificed if the built-up area is to increase. But as mentioned, the population of the city is increasing very rapidly due mainly to rural-urban migration. The population of the city reached to 10.7 million in 2001 and the population growth of Dhaka has been $56.5 \%$ in the last decade, which is very high (BBS, 2001). Understandably, these additional people have created tremendous pressure on the urban utility services and other facilities of urban life. This has resulted in an adverse effect on the suburban land use pattern and environment where a large portion of agriculture land, vegetation, water-bodies and lowland areas are converted to develop area (Islam, 2011).

\section{Trend of land use change}

The main activity of the area was agriculture which generates income for the farmers. Farmers have changed their land use from other infrastructure development sector (e.g. housing developer from real state building, large and small scale industries and road networks) that has further enhanced the land use change process in the area. It is important to study the driving forces of land use changes to understand the change process.

Table 1. Trend of the land use change pattern in the study area, 1960-2014

\begin{tabular}{|l|l|l|l|l|l|l|l|l|l|}
\hline $\begin{array}{l}\text { Land use } \\
\text { categories }\end{array}$ & $\begin{array}{l}1960 \\
\text { area } \\
\text { (ha) }\end{array}$ & $\begin{array}{l}2000 \\
\text { area } \\
\text { (ha) }\end{array}$ & $\begin{array}{l}1960-2000 \\
\text { changed } \\
\text { area (ha) }\end{array}$ & $\begin{array}{l}\text { \% of } \\
\text { changed } \\
\text { area }\end{array}$ & $\begin{array}{l}2014 \\
\text { area } \\
\text { (ha) }\end{array}$ & $\begin{array}{l}2000-2014 \\
\text { changed } \\
\text { area (ha) }\end{array}$ & $\begin{array}{l}\text { \% } \\
\text { changed } \\
\text { area }\end{array}$ & $\begin{array}{l}1960-2014 \\
\text { changed } \\
\text { area (ha) }\end{array}$ & $\begin{array}{l}\text { of } \\
\text { changed } \\
\text { area }\end{array}$ \\
\hline Built-up & 7,742 & 16,630 & 8888 & 114.80 & 24,029 & 7399 & 44.49 & 16287 & 210.37 \\
\hline Cultivated land & 13,404 & 10,395 & -3009 & -22.45 & 8,050 & -2345 & -22.56 & -5354 & -39.94 \\
\hline Vegetation & 7,615 & 5,418 & -2197 & -28.85 & 2,589 & -2829 & -52.21 & -5026 \\
\hline Water-bodies & 3,725 & 3,196 & -529 & -14.20 & 2,068 & -1128 & -35.29 & -1657 & -66.00 \\
\hline Wet/lowlands & 8,982 & 5,829 & -3153 & -35.10 & 4,732 & -1097 & -18.82 & -4250 \\
\hline
\end{tabular}

Source: Analysis from the land use map, 1960, 2000 and 2014

Table 1 shows the land use trend pattern in study area over time revealed a considerable increase in the built-up areas over the study period 1960-2014.
From the year 1960-2000, 2000-2014 and 19602014; built-up areas have increased $114.80 \%$, $44.49 \%$ and $210.37 \%$ respectively. On the other 
hand, cultivated land, vegetation, water-bodies and wet/lowlands areas have decreased in the same times/years. The spatial patterns of land use changes in the study area for 1960, 2000 and 2014 are shown in Fig.2. In 1960, wet/lowlands, cultivated land and water-bodies were the dominant land use types, and the direction of urban expansion (herein referred to as the built-up category) was northward. In 2000, the built-up category replaced most of the water-bodies and land depressions within the city as well as the cultivated land along the peripheral zone. Between 1960 and 2000, when road transportation from Dhaka to the hinterland was improved because of the construction of bridges over the rivers (Islam, 1996), urban expansion extended further to the north, northwest and to the west. Consequently, the area of cultivated land and water-bodies declined markedly during 1960 to 2000 (Islam et al., 2009).

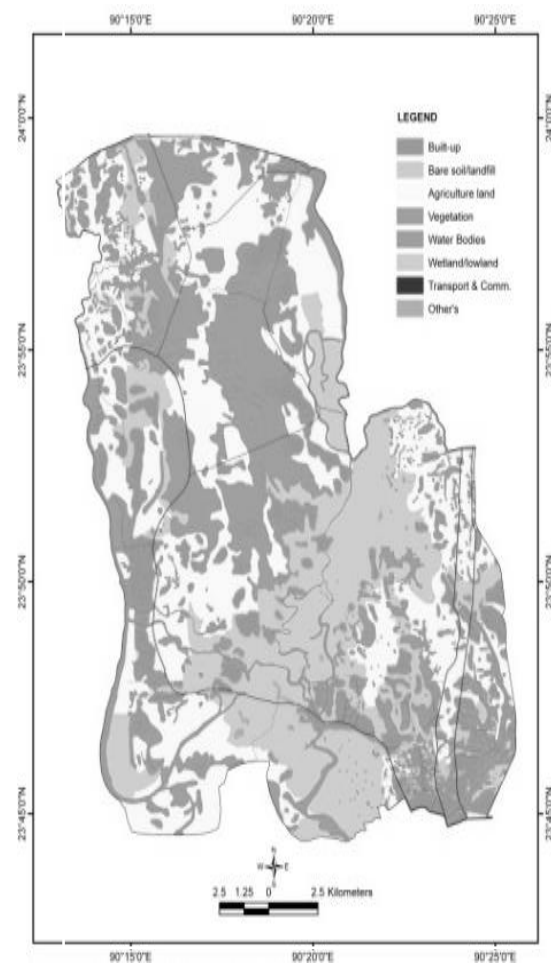

(A)

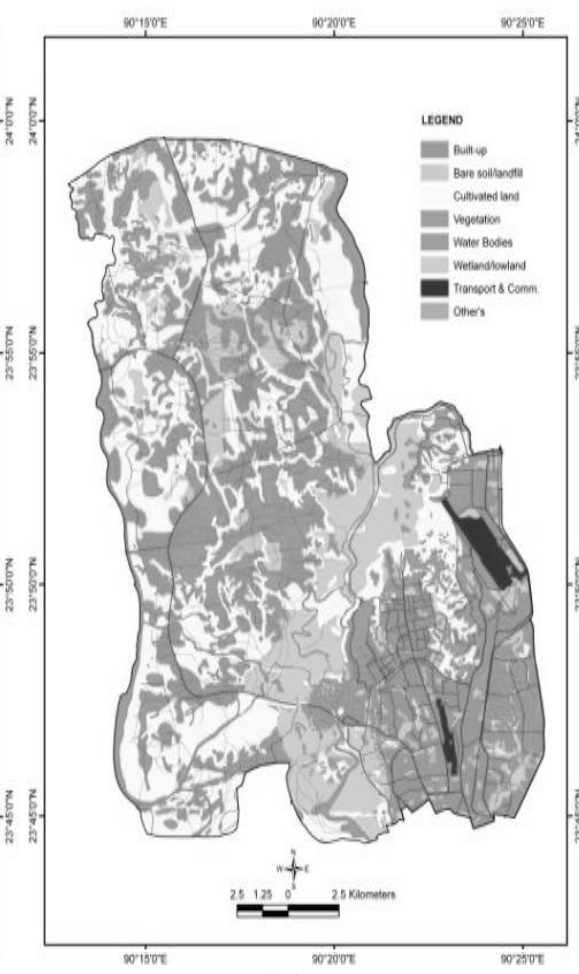

(B)

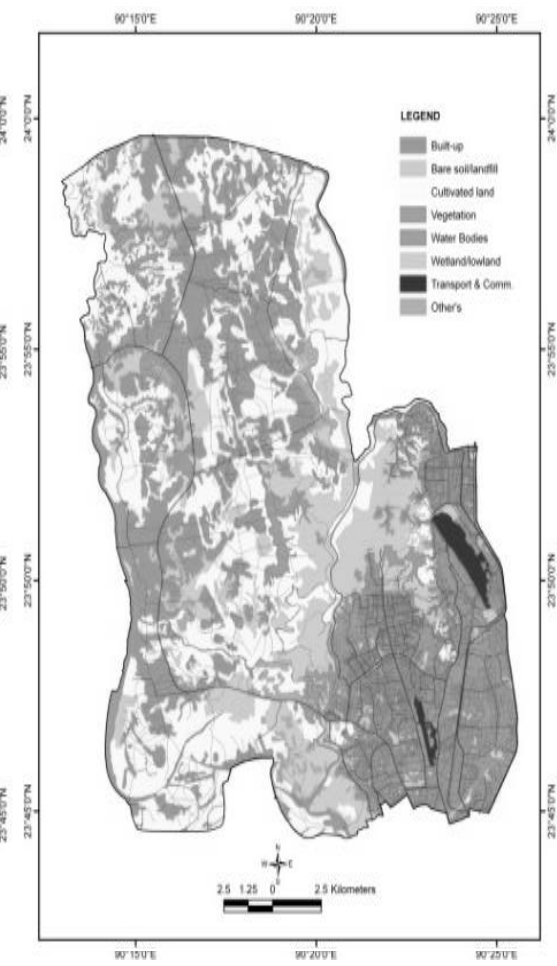

(C)

Fig. 2. Land use map in the study area (A) 1960, (B) 2000 and (C) 2014

Source: Prepared by researcher based on topographical map, 1960, Landsat TM image, 2000 and Google Image, 2014

The nature of expansion in the study area may also be associated with other factors such as topography, land use, and transportation. Figure 2 shows that the change detection built-up area revealed that 8888 ha of the urbanized area in Dhaka were before cultivated area, wet/lowlands, and water-bodies between 1960 and 2000. On the other hand, 7399, 16287 hectors of the newly urbanized areas were developed converted cultivated area, vegetation, water-bodies and wet/lowlands during the period between 2000-2014 and 1960-2014 respectively. It is found from the developing areas in Ashulia, Uttara and Amin Bazar have gradually increased from 1960 to 2014. The present study shows that the developing area in Ashulia has increased 1330 ha; during 1960 to 2000; and the developing area has decreased 64 ha during the period 2000 to 2014; for the reason that the developed area (especially bear soil/landfill area) renewed to vegetation and cultivated uses in the period. As a result taking into consideration overall developing features of Ashulia area has increased 1266 ha during the period 1960 to 2014. On the other hand in Amin Bazar area has smoothly developed into 469 ha and 1101 ha in the period of 1960-2000 and 1960-2014 respectively. Whereas developed area at Uttara has increased rapidly without any disruption. It is highly remarkable that the developing area in Uttara has increased 188 ha and 774 ha; for the period of 1960-2000 and 1960-2014.

\section{Conclusions}

It is found from the above discussion that urbanization process is rapidly intensifying in Uttara than Ashulia and Amin Bazar areas. If the present rate of urbanization in Uttara continues there would be hazards that might force to leave the area in recent future. On the other hand, there would be environmental hazards if the present rate of urbanization process continues to be taken before creating any environmental disaster. 


\section{References}

Ademiluyi, I.A.; Okude, A.S. and Akanni, C.O. 2008. An Appraisal of Land use and Land cover Mapping in Nigeria. African Journal of Agricultural Research. Vol 3 (9) 581-586.

Antrop, M. 1998. Landscape change: Plan or chaos? Landscape and Urban Planning 41:155-61.

Antrop, M. 2000. Background concepts for integrated landscape analysis. Agriculture, Ecosystems, and the Environment 77:17-28.

BBS (Bangladesh Bureau of Statistics), 2001. Statistical Year Book of Bangladesh, Ministry of Planning, Government of Bangladesh, Dhaka,

BBS (Bangladesh Bureau of Statistics). Bangladesh Population Census 1991, Urban Area Report (Dhaka: Ministry of Planning, 1997).

Fasona, M.J. and Omojola, A.S.2005. Climate Change, Human Security and Communal Clashes in Nigeria. Paper Presented at an International Workshop on Human Security and Climate Change, Asker, Norway, 21-23 June, 2007.

Islam, M.S.; Ahmed, R.; Shahabuddin, M.R; and Sheikh, A.H. 2009. Pattern of Land use Change and its Dynamics of Urban Expansion in Dhaka City, Journal of Geo-Environment, University of Rajshahi, Vol. 9, pp. 107-120.

Islam, M.S. 2011. Land use Change and Environmental Degradation in Dhaka City. Unpublished $\mathrm{Ph} \mathrm{D}$ Thesis, Institute of Environmental science, Rajshahi University, Rajshahi- 6205, pp.-289.
Islam, N. 1996. Dhaka From City to Megacity Perspective on People, Places, Planning and Development Issues, Urban Studies Programme, Department of Geography, University of Dhaka.

Lambin, E.F.; Geist, H.J. and Lepers, E. 2003. Dynamics of land-use and land-cover change in tropical regions, Environment \& Resources 28: 205-241.

Mack, S.R. and Jacobson, S.D. 1996. Core periphery analysis of the European Union: a location quotient approach, Regional Analysis \& Policy, Vol. 26(1)pp. 3-21.

Mather, A.C. 1999. Environmental Kuznets Curves and Forest Trends. Geography 84 (362), 5565.

Nassauer, J.I. 1992.The appearance of ecological systems as a matter of policy. Landscape Ecology 6:239-50.

Nassauer, J.I. 1995.Culture and changing landscape structure. Landscape Ecology 10:229-37.

Raina, P.; Joshi, D.C. and Kolarkar, A.S. 1993. Mapping of Soil Degradation by Using Remote Sensing on Alluvial Plain, Rajasthan, India. Arid Soil Research and Rehabilitation 7 (2), 145-146.

Ramankutty, N.; Foley, J.A. and Olejniczak, N.J. 2002b. People on the Land: Changes in Population and Global Croplands during the 20th Century, Ambio, 31 (3), 251-257.

Siddiqui, K.; Ahmed, K.; Awal, J. A. and Ahmed, M. 2000. Overcoming the Governance Crisis in Dhaka City, Dhaka: University Press Limited.

Wilkie, D.S. and Finn, J.T. 1996. Remote Sensing Imagery for Natural Resources Monitoring. Columbia University Press, New York. p. 295. 